\title{
PERENCANAAN DESAIN DAN RENCANA ANGGARAN BIAYA SISTEM PENYEDIAAN AIR MINUM DI DUSUN KARANGASEM, DESA MUNTUK, KECAMATAN DLINGO, KABUPATEN BANTUL
}

\author{
Sri Haryanti Prasetiyowati ${ }^{1)}$, Rosiana Indrawati ${ }^{2)}$ \\ 1) Prodi Teknik Kelautan, Fakultas Teknologi Sumberdaya Alam, Institut Teknologi Yogykarta \\ 2) Prodi Teknik Energi, Fakultas Teknik Industri, Institut Teknologi Yogykarta \\ Jl. Kebun Raya N0.39, Rejowinagun, Yogyakarta \\ email: sriharyanti@ity.ac.id 1); Rosiana.Indrawati@gmail.com 2);
}

\begin{abstract}
ABSTRAK
Penyediaan air minum merupakan salah satu kebutuhan dasar dan hak sosial ekonomi masyarakat yang harus dipenuhi oleh Pemerintah, baik itu Pemerintah Daerah maupun Pemerintah Pusat. Air bersih adalah air bersih adalah air yang memenuhi persyaratan bagi Sistem penyediaan air minum, dengan persyaratan yang dimaksud adalah persyaratan dari segi kualitas air yang meliputi kualitas fisik, kimia, biologis dan radiologis sehingga apabila dikonsumsi tidak menimbulkan efek samping

Dusun Karangasem, Desa Muntuk Kecamatan Dlingo,Kabupaten Bantul, Dusun Karangasem dengan jumlah penduduk sekitar $265 \mathrm{KK}$ atau 1040 jiwa di mana sampai saat ini kondisinya belum mendapatkan pelayanan air minum yang memmadai Dusun Karangasem mempunyai sumber air berupa sumur bor sedalam kurang lebih 80 meter dengan debit aliran 21/detik. Di Dusun Karangasem juga terdapat dua tempat wisata di mana sistem penyedian air minum belum tersedia

Metode yang digunakan dalam penelitian ini adalah metode survey dan perencanaan desain berdasarkan data primer dan data sekunder

Hasil perencanaan Sistem Penyediaan Air Minum untuk Dusun Karangasem,Desa Muntuk,Kecamatan Dlingo,Kabupaten Bantul menggunakan system pompa submersible kapasitas 5m3/jam dengan Head 100 m, 2,2 kw, 1 phase sejumlah satu buah. Pipa yang menghubungkan sumber air ke HU adalah pipa GI diameter 1,5" Pipa distribusi dari HU menggunakan pipa PVC dengan diameter 1" dan 1,5". Untuk Hidran Umum diperlukan 4 buah Hidran dengan kapasitas $5 \mathrm{~m} 3$. Sumber air (SA) berada pada koordinat $7^{\circ} 55^{\prime} 11.01$ 'S $/ 110^{\circ} 26^{\prime} 13.91^{\prime \prime} \mathrm{T}$ dengan elevasi pada 455 mdpl. Koordinat lokasi rencana Hidran umum/reservoir berada pada $7^{\circ} 55^{\prime} 14.49^{\prime \prime S} / 110^{\circ} 26^{\prime} 7.35^{\prime \prime} \mathrm{T}$ dan elevasi $481 \mathrm{mdpl}$. Elevasi/beda tinggi antara sumber air dengan reservoir $24 \mathrm{~m}$. Rencana anggaran biaya direncanakan sebesar Rp 107. 621.700,00. Pembangunan Sistem Penyediaan Air minum dilakukan secara gotongroyong dengan melibatkan masyarakat di Dusun Karangasem,Desa Muntuk,Kecamatan Dlingo,Kabupaten Bantul Kata kunci: Air Minum,,Desain Sistem Penyediaan Air Minum Perdesaan, Rencana Anggaran Biaya
\end{abstract}

\section{PLANNING DESIGN AND BUDGET PLAN OF DRINKING WATER SUPPLY SYSTEM IN DUSUN KARANGASEM, MUNTUK DESA, KECAMATAN DLINGO, BANTUL DISTRICT}

\section{ABSTRACT}

The provision of drinking water is one of the basic needs and socio-economic rights of the community that must be fulfilled by the Government, both the Regional Government and the Central Government. Clean water is clean water is water that meets the requirements for a drinking water supply system, with the requirements referred to as requirements in terms of water quality which include physical, chemical, biological and radiological qualities so that when consumed it does not cause side effects.

Dusun Karangasem, Desa Muntuk Kecamatan Dlingot, Kabupaten Bantul, Dusun Karangasem with a population of around 265 families or 1040 people, where until now the condition has not received drinking water service which is adequate. flow rate of 2 liter / sec. In Karangasem Hamlet there are also two tourist attractions where the drinking water supply system is not yet available

secondary data

The method used in this research is survey method and design planning based on primary data and

The results of the planning of Drinking Water Supply System for Dusun Karangasem, Desa Muntuk, Kecamatan Dlingo, Kabupaten Bantul use a submersible pump system with a capacity of $5 \mathrm{~m} 3 /$ hour with a head of $100 \mathrm{~m}, 2.2 \mathrm{kw}, 1$ phase of one. The pipe that connects the water source to HU is a GI pipe with a diameter of 1.5 ". The distribution pipe from HU uses PVC pipes with a diameter of 1 inchi and 1.5inchi. For General Hydrants, 4 hydrants with a capacity of $5 \mathrm{~m} 3$ are needed. The water source (SA) is at coordinates $7^{\circ} 55^{\prime} 11.01$ "S $/ 110^{\circ} 26^{\prime} 13.91^{\prime \prime} T$ with an elevation at $455 \mathrm{mdpl}$. The coordinates of the general hydrant / reservoir location are at $7^{\circ} 55^{\prime} 14.49$ "S / $110^{\circ} 26^{\prime} 7.35^{\prime \prime} T$ and an elevation of 481 masl. The elevation / height difference between the 
water source and reservoir is $24 \mathrm{~m}$. The budget plan is planned for Rp. 107. 621,700.00. The construction of a drinking water supply system is carried out in mutual cooperation by involving the community in Dusun Karangasem, Desa Muntuk, Kecamatan Dlingo, Kabupaten Bantul .

Keywords: Drinking Water, Design of Rural Drinking AWter Supply System, Budget Plan)

\section{PENDAHULUAN}

Penyediaan air minum merupakan salah satu kebutuhan dasar dan hak sosial ekonomi masyarakat yang harus dipenuhi oleh Pemerintah, baik itu Pemerintah Daerah maupun Pemerintah Pusat. Ketersediaan air minum merupakan salah satu penentu peningkatan kesejahteraan masyarakat, yang mana diharapkan dengan ketersediaan air minum dapat meningkatkan derajat kesehatan masyarakat, dan dapat mendorong peningkatan produktivitas masyarakat, sehingga dapat terjadi peningkatan pertumbuhan ekonomi masyarakat. Oleh karena itu, penyediaan sarana dan prasarana air minum menjadi salah satu kunci dalam pengembangan ekonomi wilayah.

Air bersih adalah air yang digunakan sehari-hari dan akan menjadi air minum setelah dimasak terlebih dahulu. Sebagai batasannya, air bersih adalah air yang memenuhi persyaratan bagi Sistem penyediaan air minum, dengan persyaratan yang dimaksud adalah persyaratan dari segi kualitas air yang meliputi kualitas fisik, kimia, biologis dan radiologis sehingga apabila dikonsumsi tidak menimbulkan efek samping (Keputusan Menteri Kesehatan Republik Indonesia, 2002).

Sistem Penyediaan Air Minum (SPAM) yang didasarkan pada peraturan (regulasi) Peraturan Pemerintah No. 16 Tahun 2005 serta Standar Teknis dari Ditjen Cipta Karya tentang Pembangunan Air bersih Perkotaan atau Perdesaan merupakan suatu sistem terpadu dari mulai

pengambilan air baku, pengolahan (kalau ada) sampai dengan distribusi yang di kelola dalam lingkup wilayah perkotaan atau pedesaan (Juwita, 2014)

Permasalahan mendasar yang dihadapi oleh penyelenggara SPAM Provinsi DI Yogyakarta adalah terbatasnya ketersediaan air baku yang memenuhi syarat baik kualitas, kuantitas dan kontinuitas serta masih adanya daerah yang belum terjangkau pelayanan air minum dan juga daerah rawan air minum. Selama ini, andalan pasokan air warga DI Yogyakarta kebanyakan dari perusahaan daerah air minum (PDAM) dan air hujan. Saat kemarau tiba, kekeringan hampir pasti terjadi. (Anonim, 2016)

\section{TINJAUAN PUSTAKA}

\section{Definisi Air Bersih}

Air bersih adalah air yang digunakan untuk keperluan sehari-hariyang kualitasnya memenuhi syarat kesehatan dan akan menjadi air minum setelah dimasak terlebih dahulu. Air minum adalah air yang kualitasnya memenuhi syarat kesehatan dan dapat langsung diminum.

(Radianta Triatmadja, 2008)

\section{Sistem Distribusi Air}

Sistem distribusi air bersih adalah pendistribusian atau pembagian air melalui sistem perpipaan dari penampungan air (reservoir) kedaerah pelayanan (konsumen). (Ramadan,Svita Eka Ristie, 2015)

\section{$\underline{\text { Sistem Pengaliran Air Bersih }}$}

Untuk mendistribusikan air bersih pada dasarnya dapat dipakai salah satu sistem diantara tiga sistem pengairan yang ada, yaitu:

a. Sistem Pengaliran Secara Gravitasi

Sistem ini digunakan bila tinggi elevasi sumber air bersih atau pengolahan berada jauh di atas tinggi elevasi daerah pelayanan. Dan sistem ini dapat memberikan energi potensial yang cukup tinggi hingga pada daerah pelayanan terjauh. Sistem ini merupakan sistem yang paling memuaskan dan menguntungkan karena pengoperasian dan pemeliharaannya lebih mudah.

b. Sistem Pengaliran Dengan Menggunakan Pompa

Sistem ini digunakan bila beda tinggi elevasi antara sumber air atau instalasi dengan daerah pelayanan tidak dapat memberikan tekanan air yang diinginkan/cukup, sehingga debit dan tekanan air yang diinginkan akan dipompa langsung ke jaringan pipa distribusi.

c. Sistem Pengaliran Kombinasi

Sistem ini merupakan pengaliran dimana air bersih dari sumber air atau instalasi pengolahan akan dialirkan ke jaringan pipa distribusi dengan menggunakan pompa dan reservoir distribusi, baik dioperasikan secara bergantian atau bersama-sama. (E.A.N Rahayu Utami, 2018) 


\section{Perencanaan Sistem Perpipaan}

\section{(1) Penggunaan Pipa}

Macam-macam pipa yang dipergunakan dalam perencanaan sistem distribusi air minum, sebagai berikut:

- $\quad$ Pipa Primer atau Pipa Induk (Supply Main Pipe)

Pipa primer adalah pipa yang berfungsi membawa air minum dari instalasi pengolahan atau reservoir distribusi ke satu zona atau daerah pelayanan. Pipa primer ini memiliki diameter yang relatif besar.

- $\quad$ Pipa Sekunder (Artikel Main Pipe)

Pipa sekunder adalah pipa yang disambungkan langsung pada pipa primer dan mempunyai diameter yang sama atau kurang dengan diameter pipa primer.

- $\quad$ Pipa Tersier

Pipa tersier dapat disambungkan langsung pada pipa primer atau sekunder. Gunanya adalah untuk melayani pipa servis, karena pemasangan langsung pipa servis pada pipa primer sangat tidak menguntungkan mengingat dapat terganggunya pengaliran air dalam pipa dan lalu lintas di daerah pemasangan.

- $\quad$ Pipa Servis atau Pemberi Air (Service Connection)

Pipa servis merupakan pipa yang dihubungkan langsung ke konsumen atau dapat disambungkan langsung pada pipa sekunder atau tersier. Pipa servis ini mempunyai diameter yang relatif kecil.

\section{(2) Jenis Pipa}

Beberapa jenis pipa yang umum digunakan dalam pekerjaan sistem distribusi air minum, antara lain:

a. Besi tuang (cast iron) Pipa ini biasanya dicelupkan dalam senyawa bitumen untuk perlindungan terhadap karat. Panjang biasa dari suatu bagian pipa adalah $4 \mathrm{~m}$ dan $6 \mathrm{~m}$. Tekanan maksimum pipa sebesar $2500 \mathrm{kN} / \mathrm{cm} 2$ (350 psi) dan umur pipa jika pada keadaan normal dapat mencapai 100 tahun.

b. Besi galvanis (galvanized iron) Pipa jenis ini bahannya terbuat dari pipa baja yang dilapisi seng. Umur pipa pada keadaan normal bisa mencapai 40 tahun. Pipa berlapis seng digunakan secara luas untuk jaringan pelayanan yang kecil di dalam sistem distribusi.

c. Plastik (PVC) Pipa ini lebih dikenal dengan sebutan pipa PVC (Poly Vinyl Chloride) dan di pasaran mudah didapat dengan berbagai ukuran. Panjang pipa $4 \mathrm{~m}$ atau $6 \mathrm{~m}$ dengan ukuran diameter pipa mulai $16 \mathrm{~mm}$ hingga $350 \mathrm{~mm}$. Umur pipa dapat mencapai 75 tahun.

d. Pipa beton Pipa ini tersedia dalam ukuran garis tengah 750-3600 $\mathrm{mm}$, sedangkan panjang standar 3,6-7,2 m. Pembuatan berdasarkan pada pesanan khusus. Pipa ini berumur 30-50 tahun (Makawimbang, 2017)

Dalam merencanakan suatu sistem distribuasi air minum, ada hal-hal yang perlu diperhatikan sehubungan dengan masalah perpipaan, yaitu:

1. Pemilihan Bahan Pipa

Bahan pipa yang akan dipakai dan dipasang tergantung pada faktor-faktor:

a. Harga

b. Tekanan air dalam system

c. Korosifitas oleh air dan tanah

d. Kondisi lapangan (beban lalu lintas, letak saluran air kotor dan kepadatan daerah perkotaan/pemukiman).

2. Kedalaman Dan Perletakan Pipa

Kedalaman atau penanaman pipa disesuaikan dengan data-data yang ada pada brosur pipa yang bersangkutan.

3. Tekanan Kerja Pipa

Pada kenyataan, pipa yang ditanam di dalam tanah mengalami dua tekanan yang datang dari dalam pipa itu sendiri akibat fluida yang ada dalam pipa, dan tekanan lain yang berasal dari gaya berat pelindung dan beban lain yang melewati jalan diaman pipa tersebut ditanam.

Tekanan karena fluida yang berada dalam pipa (dalam hal ini adalah air) yang paling berpengaruh adalah tekanan statisnya. Sedangkan tekanan dinamisnya sangat kecil, sehingga dapat diabaikan. Tekanan statis ini terjadi karena beda muka air antara dua titik yang ditinjau, 
yaitu muka air di reservoir dengan titik yang ditinjau, atau muka air tertinggi terhadap muka air terendah.

Tekanan yang bekerja pada dinding yang berasal dari luar dipengaruhi oleh beberapa hal, antara lain:

a. Berat beban di atas tanah, yaitu beban hidup dan beban mati (berat tanah sendiri).

b. Homogenitas lapisan tanah/pasir pelapis.

c. Konsentrasi tekanan pipa.

Pipa akan lebih mudah pecah bila pada dindingnya bekerja tanah yang terpusat (misalnya

\section{Hidraulika Aliran Dalam Pipa} dengan adanya batu/benda keras lainnya disekitar dinding pipa).

Suatu aliran dalam pipa (pipe flow) dapat terjadi jika terdapat beda tinggi energi (head). Persamaan energi antara dua penampang pipa dihitung berdasarkan persamaan berikut ini. (Triatmodjo, 2008)

$$
Z_{A}+\frac{p_{A}}{\gamma}+\frac{V_{A}^{2}}{2 g}+h_{p}=Z_{B}+\frac{p_{B}}{\gamma}+\frac{V_{B}^{2}}{2 g^{\prime}}+h_{f}
$$

dengan:

$\mathrm{Z}_{\mathrm{A}}$ dan $\mathrm{Z}_{\mathrm{B}}=$ Elevasi titik $\mathrm{A}$ dan $\mathrm{B}$ terhadap datum

$\mathrm{V}_{\mathrm{A}}$ dan $\mathrm{V}_{\mathrm{B}}=$ Kecepatan rerata pada titik $\mathrm{A}$ dan $\mathrm{B}$

$\frac{p_{A}}{\gamma}$ dan $\frac{p_{B}}{\gamma}=$ Tinggi tekanan di titik A dan $\mathrm{B}$

$\mathrm{hp}=$ Tinggi tekanan energi yang diberikan oleh pompa

$\mathrm{hf}=$ Kehilangan tekanan akibat gesekan

Kehilangan tinggi tekanan(hf) dihitung dengan menggunakan persamaan Darcy-Weisbach sebagai berikut:

$$
\mathrm{hf}=\mathrm{f} .\left(\frac{L}{D}\right) \cdot\left(\frac{V^{2}}{2 \cdot g}\right)
$$

Dengan $\mathrm{f}$ adalah suatu koefisien kekasaran pipa, yang dihitung dengan menggunakan grafik Moody.

Kehilangan tinggi tekanan yang diakibatkan oleh belokan maupun sambungan pipa dihitung berdasarkan persamaan berikut:

$$
\mathrm{H}=\mathrm{k} \frac{V^{2}}{2 . g}
$$

Dengan k adalah suatu koefisien belokan/sambungan

Secara empiris Hazen-William menyajikan suatu persamaan untuk menghitung kecepatan aliran dalam pipa, yaitu:

$$
\mathrm{V}=0,354 \cdot \mathrm{C}_{\mathrm{H}} \cdot \mathrm{I}^{0,54} \cdot \mathrm{D}^{0,63}
$$

dengan:

$\mathrm{I}=\quad$ kemiringan garis energi.

$\mathrm{C}_{\mathrm{H}}=\quad$ koefisien Hanzen-William

\section{METODE PENELITIAN}

Penelitian ini difokuskan pada pengumpulan data dan orientasi lapangan melaui survey lapangan. Metode atau urutan pelaksanaan yang akan dilakukan dalam penelitian ini adalah meliputi:

1. Pekerjaan persiapan dan Pengumpulan Data

Beberapa pekerjaan persiapan yang harus dipersiapkan guna memperlancar jalannya pelaksanaan pekerjaan adalah sebagai berikut: (Anonim, 2017)

a. Mempersiapkan surat-surat ijin dan surat-surat lainnya yang diperlukan. 
b. Mempersiapkan segala perlengkapan yang diperlukan, seperti:Alat ukur dan perlengkapannya.Kendaraan seperti sepeda motor dan mobil.Alat-alat tulis dan gambar.Komputer, printer dan sejenisnya.Kamera dan sarana dokumentasi lainnya.Alatalat lainnya yang diperlukan.

c. Mengumpulkan data lapangan (pengamatan langsung di lapangan) dan wawancara dengan beberapa masyarakat setempat maupun instansi terkait terhadap hal-hal yang diperlukan guna perencanaan.

d. Mengumpulkan data sekunder, seperti:

- Inventarisasi Rencana Pengembangan Sumberdaya Air

Data ini digunakan untuk melihat dan mengkaji upaya-upaya dalam pengembangan sumberdaya air yang sudah dilakukan, baik yang masih dalam perencanaan maupun yang sudah dilaksanakan. Selanjutnya dari data ini dapat dievaluasi untuk pengembangan sumberdaya air ke depan, sehingga kontinuitas perencanaan tetap terjaga. Inventarisasi rencana pengembangan sumberdaya air dikumpulkan dari hasil studi terdahulu yang ada pada wilayah studi.

- Inventarisasi Prasarana dan Sarana Air Bersih

Inventarisasi prasarana dan sarana dasar air bersih dilakukan untuk mengetahui prasarana dan sarana yang ada. Hasil inventarisasi digunakan sabagai dasar dalam analisis program pengembangan penyediaan air bersih dan perencanaan prasarana dan sarana air bersih.

- Inventarisasi Sumber-Sumber Air Yang Dapat Dimanfaatkan

Selain dari alur sungai, sumber air yang dapat dimanfaatkan antara lain air tanah, mata air, dan embung. Inventarisasi sumber air yang dapat dimanfaatkan dimaksudkan dalam rangka mengkaji potensi sumberdaya air yang ada, serta untuk menyusun berbagai alternatif penyediaan air bersih/air bersih bagi masyarakat.

- Data Tata Guna Lahan

Sebelum suatu perencanaan dilaksanakan, maka kondisi daerah rencana pembangunan perlu diketahui. Data ini meliputi penggunaan lahan, baik yang sudah ada ataupun yang baru dalam perencanaan. Data tataguna lahan digunakan untuk mencapai keterpaduan rencana pembangunan yang sudah ada. Selain itu data tata guna lahan juga diperlukan untuk masukan dalam analisis ketersediaan air.

- Data Demografi

Data demografi berisi data tentang kependudukan. Adapun yang dimaksud pada studi ini adalah data jumlah penduduk di wilayah penelitian dan daerah-daerah sekitarnya yang berpengaruh terhadap ketersediaan maupun kebutuhan air. Selain itu data kependudukan

2. Review studi terdahulu dan analisis data pendahuluan.

Untuk mencapai hal tersebut maka konsultan perlu mengadakan studi alternatif dengan langkahlangkah sebagai berikut:

a. Mengidentifikasi sumber-sumber air yang ada apakah sudah memenuhi persyaratan dari segi kualitas air dan mengoptimalkan apabila tersedia sumber air.

b. Apabila debit air dari sumber air yang ada tidak mencukupi maka dilakukan penentuan lokasi sumber dengan melakukan evaluasi terhadap sumber-sumber air yang ada di daerah lain.

c. Mengkaji hasil perencanaan terdahulu yang terkait dengan cakupan daerah pelayanan, tingkat pelayanan beserta kendala-kendala yang terjadi.

3. Survei pendahuluan

Survei pendahuluan antara lain meninjau/mengamati:

a. Tempat-tempat atau daerah yang membutuhkan air.

b. Keadaan masyarakat di daerah yang membutuhkan air

c. Lokasi sumber air (sumur) dan kualitas air

d. Rencana lokasi Hidran Umum

e. Rencana jalur penempatan pipa. 
f. Beberapa jenis aksesoris pipa dan pompa yang dibutuhkan.instansi terkait, desa/kecamatan serta masyarakat.

4. Pengukuran dan penggambaran hasil pengukuran maupun hasil inventarisasi.

5. Perencanaan Rencana Anggaran Biaya

\section{HASIL DAN PEMBAHASAN}

Lokasi Studi berada di Dusun Karangasem,Desa Muntuk,Kecamatan Dlingo,Kabupaten Bantul, Dusun Karangasem memiliki Kelompok Air minum dengan nama Kelompok Air Minum Sumber Makmur. Jumlah penduduk di Dusun Karangasem cukup banyak sekitar 265 KK atau 1040 jiwa di mana sampai saat ini kondisinya belum mendapatkan pelayanan air minum yang memmadai Dusun Karangasem mempunyai sumber air berupa sumur bor sedalam kurang lebih 80 meter dengan debit aliran 2 liter/detik. Di Dusun Karangasem juga terdapat dua tempat wisata di mana sistem penyedian air minum belum tersedia.

Dusun Karangasem memiliki Kelompok Air minum dengan nama Kelompok Air Minum Sumber Makmur. Jumlah penduduk di Dusun Karangasem cukup banyak sekitar 265 KK atau 1040 jiwa di mana sampai saat ini kondisinya belum mendapatkan pelayanan air minum yang memmadai Dusun Karangasem mempunyai sumber air berupa sumur bor sedalam kurang lebih 80 meter dengan debit aliran 21/detik. Di Dusun Karangasem juga terdapat dua tempat wisata di mana sistem penyedian air minum belum tersedia air bersih

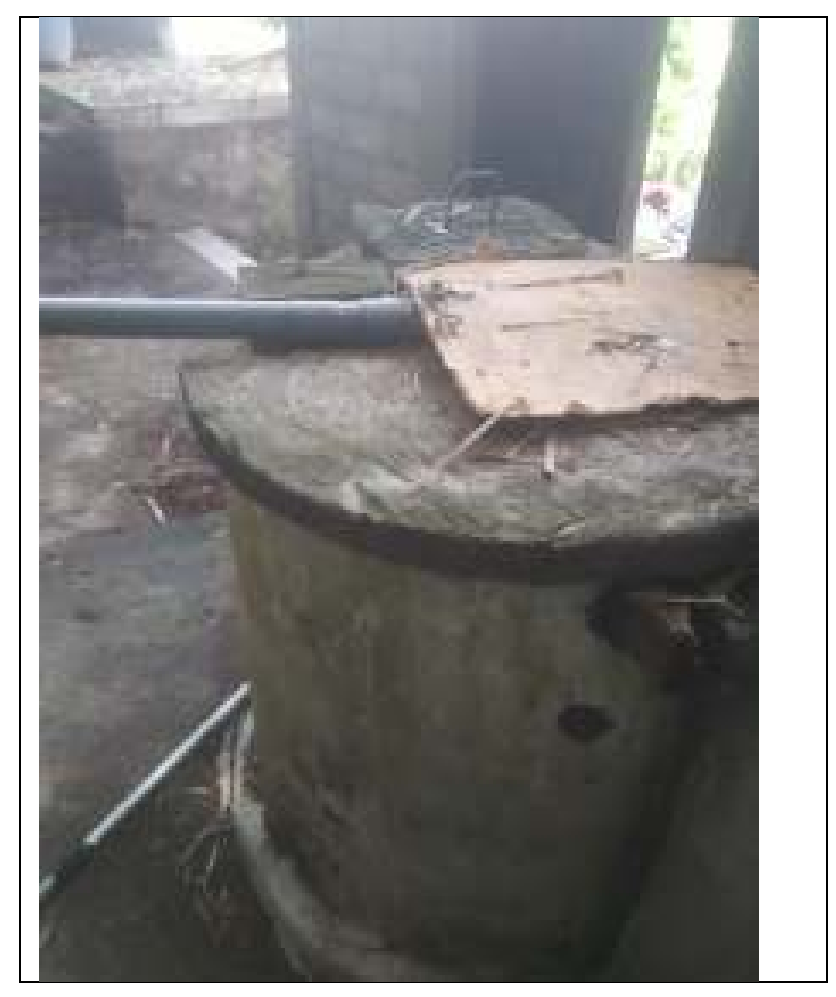

Gambar 1. Sumber air Dusun Karangasem Desa Muntuk, Kecamatan Dlingo

Rencana sistem penyediaan air minum Dusun Karangasem menggunakan tipe pengaliran dengan sistem pompa dengan kapasitas 5m3/jam dengan Head 100 m, 2,2 kw, 1 phase sejumlah satu buah. Pipa yang menghubungkan sumber air ke HU adalah pipa GI diameter 1,5" Pipa distribusi dari HU menggunakan pipa PVC dengan diameter 1" dan 1,5". Untuk Hidran Umum diperlukan 4 buah Hidran dengan kapasitas 5m3. Sumber air (SA) berada pada koordinat $7^{\circ} 55^{\prime} 11.01^{\prime \prime S} / 110^{\circ} 26^{\prime} 13.91^{\prime \prime T}$ dengan elevasi pada $455 \mathrm{mdpl}$. Koordinat lokasi rencana Hidan umum/reservoir berada pada $7^{\circ} 55^{\prime} 14.49^{\prime \prime} \mathrm{S} / 110^{\circ} 26^{\prime} 7.35^{\prime \prime} \mathrm{T}$ dan elevasi $481 \mathrm{mdpl}$. Elevasi/beda tinggi antara sumber air dengan reservoir $24 \mathrm{~m}$. 


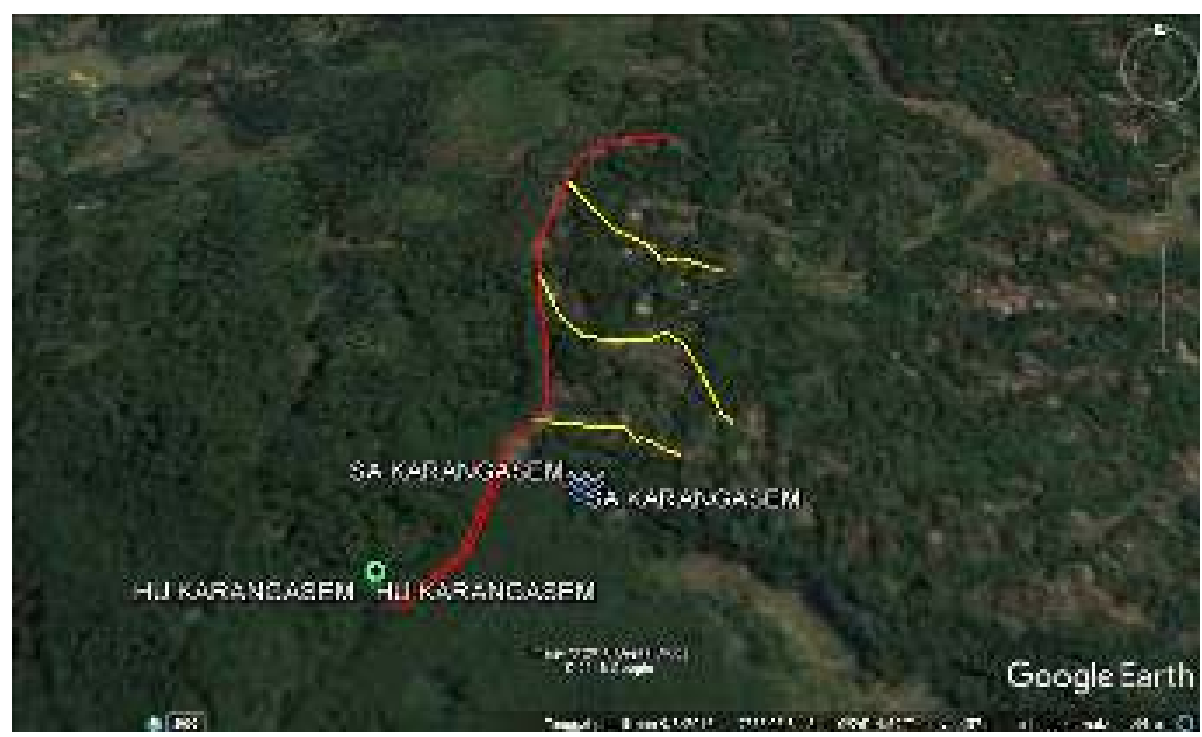

Sumber: Survey lapangan, 2017

Gambar 2. Rencana Jaringan Perpipaan SPAM Perdesaan Dusun Karangasem Desa Muntuk, Kecamatan Dlingo

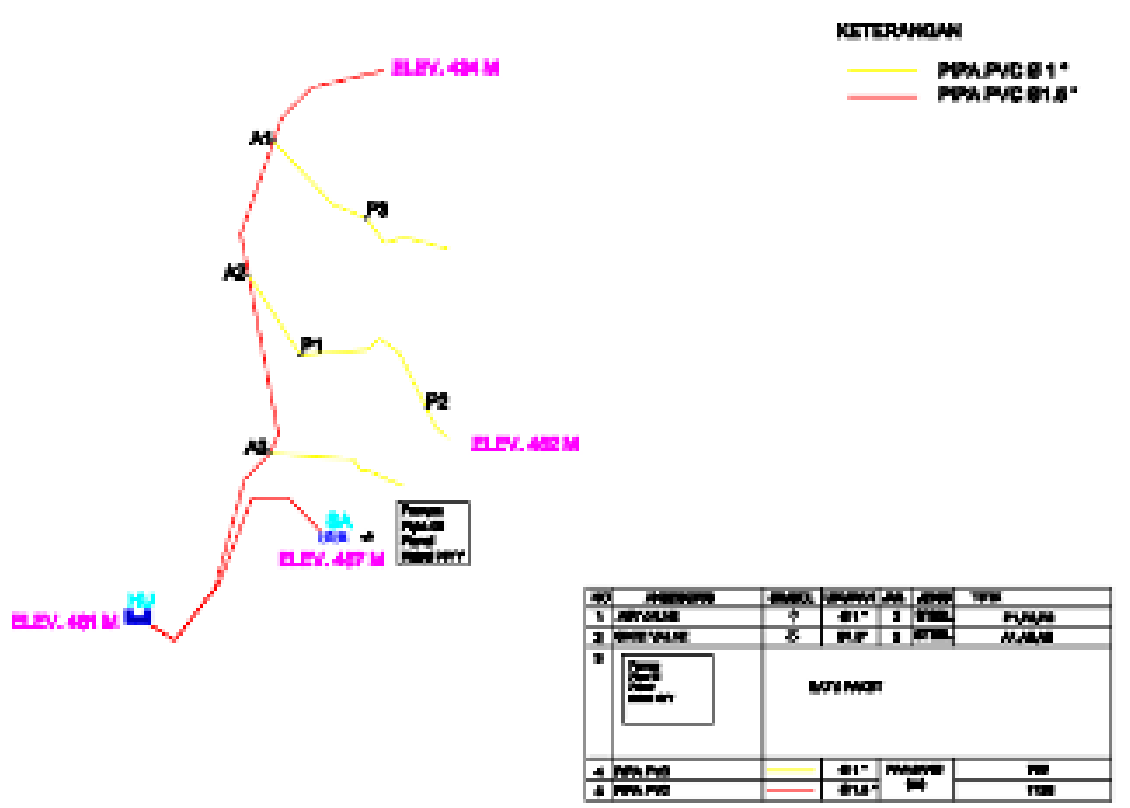

GTUAG PENEMPATAN DAN PEMASANGAN PIPA

KARANG ASEM, KAB. BNWTUL

Sumber:Hasil Analisis, 2017

Gambar 3. Desain Jaringan Perpipaan dan aksesorie Pipa SPAM Perdesaan

Dusun Karangasem Desa Muntuk, Kecamatan Dlingo

Dari hasil survey aksesories pipa dan juga kebutuhan reservoir atau Hidaran umum. Spesifikasi dari material yang digunakan mengikuti semua persyaratan yang ditentukan dalam rencana kerja dan syarat-syarat termasuk standar material yang akan dipakai yang mengacu pada SNI ( Standar Nasional Indonesia, SII ( Standar Industri Indonesia ). Beberapa jenis material yang digunakan dalam perencanaan Ssistem Penyediaan Air Minum di Dususn karangasem anatara lain Ppipa GI, Pipa PVC, gate valve, Hidrane Polythlene, Pompa submersible. Panel 1 phase, Kabel NYY 4x4 ,Air Valve 1" dan Manometer 1,5". Detail anggaran dan spesisfikasi material dapat dilihat pada tabel 1 berikut

\section{Tabel 1. Rencana Anggaran Biaya Jaringan Perpipaan}




\begin{tabular}{|c|c|c|c|c|c|}
\hline No & Nama Barang & Volume & Satuan & $\begin{array}{l}\text { Harga satuan } \\
\text { (Rp) }\end{array}$ & Total (Rp) \\
\hline 1 & Pipa GI diameter $1,5^{\prime \prime}$ & 72 & $\mathrm{~m}$ & 56,000 & $4,032,000$ \\
\hline 2 & $\begin{array}{l}\text { Pipa PVC S.12,5 SNI } \\
1,5 "\end{array}$ & 1129 & $\mathrm{~m}$ & 16,500 & $18,628,500$ \\
\hline 3 & Pipa PVC S.12,5 SNI 1" & 768 & $\mathrm{~m}$ & 12,000 & $9,216,000$ \\
\hline 4 & Gate Valve 1,5" & 3 & bh & 190,000 & 570,000 \\
\hline 5 & $\begin{array}{l}\text { Hidran Polyethilene } 5 \\
\text { m3 }\end{array}$ & 4 & bh & $8,400,000$ & $33,600,000$ \\
\hline 6 & $\begin{array}{l}\text { Pompa submersible } 2,2 \\
\text { Kw,Kapasitas } 5 \mathrm{~m} 3 / \mathrm{jam}, \\
1 \text { Phase }\end{array}$ & 1 & bh & $31,500,000$ & $31,500,000$ \\
\hline 7 & Panel 1 phase $20 \mathrm{~A}$ & 1 & bh & $4,400,000$ & $4,400,000$ \\
\hline 8 & Kabel NYY 4x4 & 100 & $\mathrm{~m}$ & 49,500 & $4,950,000$ \\
\hline 9 & Air Valve 1" & 3 & bh & 158,400 & 475,200 \\
\hline \multirow[t]{3}{*}{10} & Manometer 1,5" & 2 & bh & 125,000 & 250,000 \\
\hline & Jumlah & & & & $107,621,700,00$ \\
\hline & Terbilang & & & & $\begin{array}{l}\text { (Seratus Tujuh } \\
\text { puluh juta } \\
\text { Enam ratus } \\
\text { Dua puluh satu } \\
\text { ribu Tujuh ratus } \\
\text { rupiah) }\end{array}$ \\
\hline
\end{tabular}

\section{Sumber: Hasil Analisis data primer,2017}

Dari hasil perhitungan diperlukan anggaran sebesar Rp 107.621.700,00 untuk penyediaan pipa dan aksesoriesnya. Pendanaan diberikan pemerintah melaui Program SPAMDES dari PUP ESDM DIY Tahun Anggaran Tahun 2017. Untuk tenaga kerja tidak dimasukkan ke dalam rencana anggararan kareana akan dilakakan secara gotong-royong.

\section{KESIMPULAN}

1. Dusun Karangasem,Desa Muntuk,Kecamatan Dlingo,Kabupaten Bantul, kondisinya belum mendapatkan pelayanan air minum yang memadai juga terdapat dua tempat wisata di mana sistem penyedian air minum belum tersedia.

2. Dusun Karangasem mempunyai sumber air berupa sumur bor sedalam kurang lebih 80 meter dengan debit aliran 21/detik. Di Dusun Karangasem

3. Rencana desain sistem penyediaan air minum di Dusun Karangasem dengan sistem pompa dengan kapasitas 5m3/jam dengan Head $100 \mathrm{~m}, 2,2 \mathrm{kw}, 1$ phase sejumlah satu buah.

4. Jenis pipa yang digunakan anatara lain pipa GI diameter 1,5 inchi dan pipa PVC dengan diameter 1 inchi dan 1,5 inchi.

5. Sistem Penyediaan Air di Dusun Karangasem,Desa Muntuk,Kecamatan Dlingo,Kabupaten Bantul direncakan melayaani $265 \mathrm{KK}$ atau 1040 jiwa dan dua tempat wisata

6. Rencana anggaran biaya prencanaan Sistem Penyediaan Air Minum Perdesaan di Dusun Karangasem,Desa Muntuk,Kecamatan Dlingo,Kabupaten Bantul sebesar Rp 107.621.700,00

\section{UCAPAN TERIMA KASIH}

Ucapan terima kasih Kepada:

1. Dinas PUP-ESDM DIY

2. Pamaskarta Kabupaten Bantul

3. Kelompok Air minum Sumber Makmur

4. LP2M Institut Teknologi Yogyakarta 


\section{DAFTAR PUSTAKA}

Anonim, Laporan Akhir Pengadaan Pipa dan Aksesories Spamdes Tahun Anggaran Tahun 2016, Dinas PUP-ESDM DIY, 2016

Anonim, Laporan Akhir Pengadaan Pipa dan Aksesories Spamdes Tahun Anggaran Tahun 2017, Dinas PUP-ESDM DIY, 2017

E.A.N, Rahayu Hutami,.Eko Noerhayati (2018). Dampak Perencanaan Sistem Jaringan Distribusi Air Bersih Desa Ulu Konahewa Kecamatan Samaturu Kab. Jurnal Rekayasa Sipil, 6(1), 9-17.

Juwita, Dwi May, Repinka Cornelia, Aqmal Satrio Dirgantara, Suprapto, Ismadi Raharjo (2014) Perencanaan Sistem PenyediaanAir Minum (SPAM) Pedesaan Dusun IV Desa Sumberejo Kabupaten Tanggamus,Jurnal Ilmiah Teknik Pertanian, 6 (2), 71-142

Keputusan Menteri Kesehatan Republik Indonesia no.907/MENKES/SK/VII/2002

Makawimbang, Anastasya Feby, Lambertus Tanudjaja, Eveline M. Wuisan (2017),Perencanaan Sistem Penyediaan Air Bersih Di Desa Soyowan Kecamatan Ratatotok Kabupaten Minahasa Tenggara, Jurnal Sipil Statik 5 (1), (31-40)

Ramadhan, Svita Eka Ristie Jeffry S.F Sumarauw, Eveline M. Wuisan (2015) Perencanaan Sistem Penyediaan Air Bersih Di Desa Manembo Kecamatan Langowan Selatan Kabupaten Minahasa . Jurnal Ilmiah Teknik Sipil 13 (62)

Radianta Triatmadja 2008. Sistem Penyediaan Air Minum Perpipaan, DRAFT, Yogyakarta. Bab 1(112), Bab 2 (11-19), Bab 3(37-40), Bab 4(1-28)

Triatmodjo, Bambang.2008.Hidrolika I.Yogyakarta : Beta Offset 